\title{
Do Voting Advice Applications Have an Effect on Electoral Participation and Voter Turnout? Evidence from the 2007 Swiss Federal Elections
}

\author{
Andreas Ladner and Joëlle Pianzola \\ Institutional Policies, IDHEAP Lausanne, Route de la Maladière 21, 1022 \\ Chavannes-près-Renens \\ andreas.ladner@idheap.unil.ch, pianzola@nccr-democracy.uzh.ch
}

\begin{abstract}
Voting Advice Applications (VAAs) render a valuable platform for tackling one of democracy's central challenges: low voter turnout. Studies indicate that lack of information and cost-benefit considerations cause voters to abstain from voting. VAAs are online voting assistance tools which match own political preferences with those of candidates and parties in elections. By assisting voters in their decision-making process prior to casting their votes, VAAs not only rebut rational choice reasoning against voting but also narrow existing information gaps. In this paper we examine the impact of VAAs on participation and voter turnout. Specifically, we present results on how the Swiss VAA smartvote affected voter turnout in the 2007 federal elections. Our analyses suggest that smartvote does have a mobilizing capacity, especially among young voters who are usually underrepresented at polls. Moreover, the study demonstrates how VAAs such as smartvote do affect citizen's propensity to deal with politics in general.
\end{abstract}

Keywords: e-democracy, voter turnout, electoral participation, Voting Advice Applications (VAAs).

\section{Introduction}

Low voter turnout is a familiar phenomenon in most advanced democracies. Switzerland, in particular, is among those countries that finish last on the voter turnout ranking list. Since 1975, electoral participation has never been higher than 50 percent. $^{1}$ The reasons for low voter turnout are often attributed to indifference, disenchantment or even approval towards current politics, but empirical research has not yet been able to find consensus on the matter. Scholars are divided on the reasons for decline of voter turnout and speculate on approaches to enhance participation. Disagreement even exists on whether low voter turnout is in fact a problem for democracy (e.g. [1]) or simply a systemic side effect (e.g. [2]). In the end, most scholars do, however, agree that low political participation does counteract those

1 http://www.bfs.admin.ch/bfs/portal/de/index/themen/17/02/

blank/key/national_rat/wahlbeteiligung.html 
concepts of democracy which have inclusive participation among their funding normative principals.

Switzerland does not only deal with low levels of political participation, it has also been identified among those countries with low levels of political knowledge among its citizens, especially among the young [3]. That lack of participation in the democratic process and lack of knowledge and interest in politics is not necessarily favorable for democracy goes without saying. Dalton [4] underlines this argument with paraphrasing Thomas Jefferson who stressed that a well-informed electorate is the most important constraint on government. Thus, from a normative perspective, it can be argued that an informed electorate matters for reasoned vote choices and accordingly for the quality of representation. Empirically, it has been indicated that non-voters tend to have less information about politics than voters [5]. Hence, higher voter turnout could be achieved by raising information and interest. But how can this be achieved? One step might be to bring the electoral process closer to the citizens and motivate them to engage in it. As this paper will stress, one potential answer to this challenge could lie within the use of new internet tools which help citizens to gather information and support them in their decision making process during elections.

The coming of age of modern communication technologies not only immersed itself into our daily lives, it also gave leeway to modernize the process of casting ballots. The implementation of remote electronic voting (e-voting) was hoped to boost electoral participation, especially among the young. But these high hopes have so far not been met by reality. First of all, the introduction of e-voting systems has been limited to a few countries, since implementation difficulties have been greater than expected. Second, those countries that did implement e-voting procedures did not experience significant higher voter turnout ([6], [7], [8]). The following reasons serve as an explanation for this: First, the so called "preaching to the converted"- effect. In other words, the introduction of e-voting only reached those voters who were already interested in politics and would have gone to the polls anyway [9]. Second, e-voting was supposed to minimize voting efforts and hence attract those who, according to rational choice theory, do not vote because the cost-benefit ratio of voting does not pay off [10]. It is questionable which part of the voting process causes voters to invest time and might therefore restrain them from voting. It seems that e-voting does not necessarily reduce costs to voters in comparison to the traditional act of voting. This holds especially true in countries where postal voting is the standard, such as Switzerland [11]. Or as Norris [6] puts it, "the simple Victorian postage stamp beats the high-tech microchip hands down". It can be assumed that the process of decisionmaking prior to casting the vote is much more time consuming and costly than the actual act of voting. To gather information about politics, candidates and parties and their respective programs, evaluate and discuss the different policy stances is what asks for time investment. The so-called "pre-voting sphere" (process of gathering information and opinion formation before the election day) should therefore not be neglected when assessing the effects of e-democracy on voter turnout [12]. Research efforts on this matter, however, have so far been scarce.

Voting Advice Applications (VAAs) are such e-democracy tools which aim to assist voters in their decision-making process. VAAs have become astonishingly popular in a large number of advanced democracies in recent years. For example, the 
Dutch Stemwijzer was used by $40 \%$ of the Dutch electorate in 2006 and the German Wahl-o-Mat has attracted more than 10 million users since its introduction in 2002 $[13] .^{2}$ In order to gain more empirical insight on the effects of these tools on electoral participation, a particular VAA and its impact will be examined. This paper will focus on smartvote (www.smartvote.ch), a well-established Swiss VAA which helps voters to select candidates and parties on the basis of their own political values and preferences. Since smartvote is meant to support voters in their decision-making process, the question is whether the VAA can serve as a means of increasing interest in politics in general, support voters in gathering information and eventually affect participation and voter turnout.

The paper is organised as follows: first, theoretical considerations and evidence from other countries with regard to VAAs are discussed. Second, smartvote and its users are introduced. Third, results on its effect on participation and voter turnout in the 2007 Swiss federal elections are presented. And last, results will be discussed with an outlook on future research opportunities.

\section{Theoretical Considerations and Evidence from Other Countries}

Can VAAs such as smartvote motivate citizens to cast their vote? Do they increase interest in politics and consequently affect electoral participation? Before getting to the bottom of these questions, it is helpful to dissect why citizens abstain from voting. For the case of Switzerland, Bühlmann et al. [14] compiled six different types of nonvoters based on a post-electoral survey of the 1999 Swiss federal elections: the uninterested citizens (33\%), the alienated citizens (7\%), the social isolated citizens (10\%), the incompetent citizens (14\%), the protesting citizens (17\%) and the alternatively participating citizens $(19 \%)$.

Fivaz [15] sees potential for the following three groups of non-voters to be positively affected by VAAs. First, the uninterested citizen: The uninterested citizen has problems finding a party that fits its preferences. Since VAAs allow voters to match their preferences with parties, such tools could return the uninterested citizen to politics. Second, the social isolated citizen is marked by a low level of income and education as well as low social status resulting in an overall social disintegration. VAAs offer simple access to information and allow comparisons of own opinions to those of the political class, independent of knowledge, social or financial status, and personal network. Hence, they increase the possibilities of bringing socially isolated

${ }^{2}$ Further VAAs; in Holland: Stemwijzer (www.stemwijzer.nl), Kieskompas (www. kieskompas.nl); in Germany: Wahl-o-Mat (www.wahlomat.de). Further examples for VAAs are Austria: Wahlkabine (www.wahlkabine.at) and Politikkabine (www.politikkabine.at), in the United Kingdom: Who Do I Vote for? (www. whodoivotefor.co.uk); in the United States: Project vote smart (www.votesmart.org), Glassbooth (www.glassbooth.org) and On the Issues (www. ontheissues.org); in Italy: Openpolis (www.openpolis.it); in Lithuania: Manobalsas (www.manobalsas.1t); in Bulgaria: Koimipasva (www. koimipasva.bg); in Canada: smartvote Ottawa (www.smartvoteottawa.ca); for general supra-national level: Political Compass (www.politicalcompass.org) and EU-Profiler (www. euprofiler.eu); and there is a VAA in Iraq as well: Niqash (www.niqash.org). 
citizens back into politics. And third, the incompetent citizen, who does not feel competent enough to participate in voting: The main reason for abstinence here is lack of information. VAAs' principal asset is bundling and offering information on politics and policies which are otherwise hard to gather. Again, VAAs might give the incompetent citizen the information needed to re-enter politics. Taken all together, VAAs might be appealing to about half of the citizens who tend to abstain from voting. Although these propositions are highly speculative, there is evidence that VAAs do attract a specific group of voters who are usually underrepresented at elections: the young. Although voter turnout among the young has been steadily increasing over the last years in Switzerland, their relative participation rate is still low [16]. Studies on VAAs in the Netherlands, Finland, Germany and Switzerland conclude that especially the young are prone to use VAAs and that awareness and usage of VAAs is generally highest among the young and the well educated ([17], [18], [19], [20]). Since young citizens tend to be part of non-voters, electronic tools such as VAAs might offer a chance to mobilize its most frequent users into politics.

Further indicators for the mobilization capacities of VAAs are their ability to increase motivation and interest in politics among its users. A study on a German VAA called Wahl-O-Mat found that almost half of the users were motivated to gather more political information after they had used the VAA [19]. For the 2006 parliamentary elections in the Netherlands, Ruusuvirta and Rosema [17] found that the local VAA Stemwijzer helped those voters to make a voting choice who did not know in advance if they were going to vote. The survey data from the Netherlands suggest that voters do use VAAs to guide them in their vote decision-making [17]. Moreover, VAAs have become the most important source of information for younger voters in Finland ([17], [21]).

Although several studies suggest the mobilizing capacity of VAAs, it has to be kept in mind that figures are always subject to controversy. All data rely on the correctness of submitted answers by users, which may or may not be accurate. Whether users mobilized by the use of VAAs actually cast their vote cannot be determined with certainty. Furthermore, Ruusuvirta and Rosema [17] point out that the effects of VAAs on electoral participation are hard to prove. The difficulty lies in the causal mechanisms - whether the use of the VAA motivated to cast a vote or whether the motivation to vote led to the usage of a VAA is hard to distinguish. Nevertheless, it seems that VAAs do have an effect on electoral participation, but we have yet to figure out the extent of it.

From a theoretical perspective there are substantial arguments in favour of VAAs impact on electoral participation. What gives rise to optimism with regard to VAAs impact on voter turnout is its main attribute of offering political information. VAAs render the unique possibility of gaining access to information about politics, political parties and candidates in a condensed and efficient way. This plays well with the rational choice argument. Acquiring and processing information is subject to costs, which, according to rational choice theory, individuals only accept if the benefits are promising [22]. Through increasing the amount of easily available information, VAAs reduce the costs of information gathering and thus increase the likelihood of voting (e.g. [17]).

Empirical findings also indicate that information is crucial for electoral behavior. Lutz [5] has analyzed low turnout in (direct) democracy. His findings underline the 
importance of information for democratic processes and outcomes. Especially in countries with multiparty systems, the complexity of required information to make an informed voting choice is high. As Walgrave et al. [13] put it, "the fact that VAAs seem to be popular, especially in countries with large and fragmented, and thus complicated, party systems, indicates that information is key". Lutz [5] finds that nonvoters tend to be less informed and speculates that higher turnout could be achieved by raising interest and information. Previous literature on political knowledge has also come to this conclusion: higher levels of political information are linked to increased voter turnout ([23], [24]). Generally, political scientists have been indicating that a high level of information among citizens is a precondition for the well functioning and the stability of a democracy [25].

VAAs might furthermore add value to democratic processes for those aiming at the best possible integration of citizen's political preferences. Walgrave et al. [13] argue that VAAs spur issue-voting, in which voters cast their vote based on the "perceived proximity between their own position on an issue and the party they vote for". In other words, VAAs offer easy access to information about party and candidate policy preferences and can therefore lead to a voting choice based on issues. Since party affiliations have become weaker in all advanced democracies [26], voters tend to be more prone to seeking clues that affiliates them with a party or candidate in order to make a voting choice. The issue-matching module of VAAs might thus increasingly serve as an electoral guide for voters, allowing them to elect exactly those representatives that do share similar policy preferences. In other words, VAAs might even have an impact on the quality of electoral decisions and consequently representation.

\section{VAA smartvote}

\section{Functioning and Use}

The VAA smartvote (www.smartvote.ch) was introduced by Politools ${ }^{3}$ in the forefront of the 2003 federal elections in Switzerland. Since then it was also offered on the occasion of more than twenty elections on regional and local level in Switzerland as well as in different foreign countries (most recently for the federal elections in Luxembourg in June 2009). The core of smartvote is, similar to most VAAs, the issue-matching module. In order to gather the necessary data for issuematching, both the candidate and the voter answer a set of pre-assembled questions ${ }^{4}$.

About six weeks before the elections the smartvote website for the specific election is made accessible to voters and leads them in three steps to their individual voting recommendation. The voters first have to specify their own political profile by answering the same questionnaire as the candidate did. For each question additional background information and explanations including pros and cons are provided on the website. Secondly, voters have to select the constituency in which they vote, respectively for which they want to receive a voting recommendation. Depending on

\footnotetext{
${ }^{3}$ Politools is a private association providing information about political processes for citizens: www. politools . net (German).

${ }^{4}$ The voter can choose between a "rapid version" consisting of 36 questions and a "deluxe version" consisting of 73 questions. Candidates answer a set of 73 questions.
} 
the electoral system they can also decide whether they wish to receive a voting recommendation for lists/parties or for individual candidates. Finally, smartvote compares the answers of the voter with the answers of all candidates including the weighting factors the voter has given to the questions. The higher the congruence of the answers between a voter and a candidate, the more "matching points" a candidate gets. This process is repeated over all questions and for every candidate in the selected constituency and results in a voting recommendation in form of a list with a decreasing ranking of the candidates according to their total matching score. If a voter wishes to receive a voting recommendation for lists/parties the procedure is similar. Here smartvote uses the mean value of all answering candidates of a list or party.

Additional features are provided by smartvote to visualize voting recommendations and party or candidate profiles; the so-called smartspider (see Figure 1) and smartmap charts. Both analytical graphs are based on the candidates' and the user's answers to the smartvote questionnaire respectively. The smartspider shows the agreement or disagreement on eight major political issue dimensions formulated as political goals (e.g. more law and order, more environmental protection, or a strong welfare state) in a spider net graph. The values on the eight axes range from 0 to $100-0$ standing for complete disapproval of the formulated political goal and 100 for full approval. The smartmap is based on a system of coordinates with two major ideological cleavages serving as axes - the "north-south axis" for the cleavage between liberal and conservative standpoints and the "west-east axis" for the left-right cleavage.
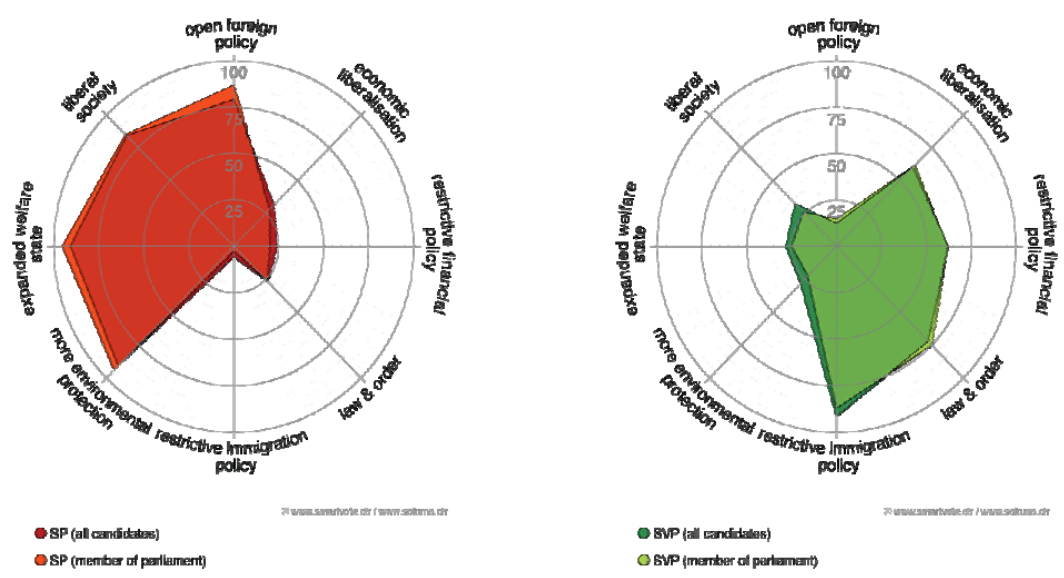

Fig. 1. Example for smartspider of Swiss Democrats (SP) and Swiss People's Party (SVP) for the 2007 Swiss federal elections

Source: www. smartvote.ch

\section{smartvote Users}

The use of smartvote increased severely since its introduction in 2003. In the 2007 federal elections absolute figures almost quadrupled and increased from 255'000 uses 
in 2003 to $938^{\prime} 403$. This results in a smartvote use index ${ }^{5}$ of almost $40 \%$ of voter turnout in 2007. These figures, however, have to be corrected for multiple counting's, where users have generated more than one voting recommendation. Hence, the estimation for the real number of voters using smartvote in 2007 is $375^{\prime} 000$. This means that about $16 \%$ of those who went to the polls in 2007 were smartvote users. A similar trend can be observed by candidates running for office. In 2003, half of the candidates answered the smartvote questionnaire, while by $200785 \%$ of all candidates running for office participated on the smartvote website [20]. These statistics indicate the increased popularity of smartvote among the Swiss electorate.

Regarding socio-demographic characteristics, the typical smartvote users are male, younger and tend to have a higher education and explicitly more income (see Table 1).

Table 1. Socio-demographic characteristics of smartvote users, 2007 Swiss federal elections

\begin{tabular}{ll}
\hline Characteristics & smartvote users (in \%) \\
\hline Gender & \\
\hline Men & 67 \\
Women & 33 \\
\hline Age & 21 \\
\hline 18-24 years old & 28 \\
25-34 years old & 21 \\
35-44 years old & 15 \\
45-54 years old & 10 \\
55-64 years old & 4 \\
65-74 years old & 1 \\
75+ years old & \\
\hline Level of education & 3 \\
\hline Low & 54 \\
Medium & 43 \\
High & \\
\hline Household income (in Swiss Francs) & 5 \\
\hline -3'000 & 11 \\
3'001-5'000 & 40 \\
5'001-9'000 & 44 \\
9'001+
\end{tabular}

Source: NCCR "Democracy", IP16 "smart-voting", post electoral survey among smartvote users [15].

Selects ${ }^{6}$ data on the 2007 Swiss federal elections indicated that voter groups with a turnout rate below average primarily consisted of women, young voters and voters with low or medium levels of education [16]. The young are the congruent part

${ }^{5}$ Smartvote use index: absolute number of voting recommendations per election in relation to voter turnout. Absolute voter turnout in 2007: 2'373'071

(http://www.bfs.admin.ch/bfs/portal/de/index/themen/17/02/

blank/key/national_rat/wahlbeteiligung.html).

${ }^{6}$ The Swiss Electoral Studies Selects is an electoral research project of several political science departments of Swiss Universities that started in 1995 (http: / /www. selects. ch). 
between smartvote users and the voter group with low turnout rates. Hence, if VAAs manage to mobilize its young users, a particularly strong impact on turnout could be expected.

\section{4 smartvote and Voter Turnout}

For various reasons the impact of smartvote on electoral participation and over all voter turnout is not easy to evaluate. Only a part of the Swiss electorate uses smartvote and therefore representativity in our survey data is not given. However, since we are interested whether the use of smartvote affected electoral participation, presenting the survey data of users is sufficient.

The data presented here has been collected in a pre-voting and a post-voting survey among smartvote users in the 2007 federal elections. 27'000 smartvote users participated in our online surveys. To approach the question whether smartvote affected electoral participation and turnout, we will first have a look at evidence from aggregate level and then turn our attention to individual level data.

\section{Evidence from Aggregate Level Data}

As mentioned, voter turnout is extremely low in Switzerland compared to other countries. In the last few elections, however, there has been a slight increase from the all time lowest score of $42.2 \%$ in 1995 to $48.3 \%$ in $2007 .^{7}$

Since smartvote was not introduced before the 2003 Swiss federal elections, it cannot be made responsible for the whole increase. However, there are some indications on the aggregate level that smartvote might affect overall turnout. In the two larger cantons of Zurich and Berne, where smartvote was particularly popular during the 2007 federal elections, the increase in turnout was above average. Furthermore, turnout among younger voters has severely increased over the years [16]. Since smartvote attracts especially the young, it seems interesting to trace whether the tool has a mobilizing capacity among this voter cohort. In order to evaluate in how far these trends are connected, evidence from individual data need to be taken into account.

\section{Evidence from Individual Level Data}

In general: smartvote is used by those who already participate, have a higher political interest and know more about politics than the average voter (see Table 2).

From the Swiss Electoral Studies Selects we know that of those who did use smartvote, $72.7 \%$ also participated in the 2007 elections, whereas from those who did not use smartvote, only $46.4 \%$ participated. Furthermore, among those who did use smartvote, $30 \%$ are very interested in politics and $50 \%$ are rather interested in politics. This leaves about $20 \%$ of smartvote users who consider themselves as not interested in politics, compared to about $38 \%$ of voters in general.

\footnotetext{
7 Voter turnout 1999: 43.3\%, Voter turnout 2003: 45.2\%, (http: / /www.bfs.admin.ch/bfs/portal/de/index/themen/17/02/ blank/key/national_rat/wahlbeteiligung.html).
} 
Table 2. Political interest and knowledge among voters and smartvote users

\begin{tabular}{lll}
\hline & Voters (\%) & smartvote users (\%) \\
\hline Interest in politics & & \\
\hline High & & \\
Rather high & 16.5 & 30.5 \\
Rather low & 45.3 & 48.0 \\
Low & 26.3 & 19.0 \\
\hline Political knowledge & 11.9 & 2.5 \\
\hline High & & \\
Rather high & 6.6 & 16.2 \\
Medium & 19.0 & 26.4 \\
Rather low & 26.9 & 25.2 \\
Low & 29.9 & 16.8 \\
\hline
\end{tabular}

Note: $\mathrm{N}=4392$ for voters and 333 for smartvote users

Source: Swiss Electoral Studies 2007

The theoretical argument has been put forward that VAAs ease access to information about parties and candidates and should therefore be a catalyst for turnout. smartvote users have been asked whether the VAA improved their basis of information, whether it motivated them to search for more information about political issues, candidates and parties and whether smartvote motivated them to discuss politics, candidates and parties with other citizens. Almost 55\% of the users claimed that smartvote improved their basis of information and for an additional 30\% this was a least partially true $(\mathrm{N}=17331)$. Quite important parts of the users got particularly motivated to search for more information about specific political issues $(16.4 \%$ true, $32.6 \%$ rather true, $\mathrm{N}=17382)$ and about specific candidates or parties $(20.7 \%$ true, $35.9 \%$ rather true, $\mathrm{N}=17376$ ). And over $65 \%$ of the users claimed that smartvote motivated them to discuss political issues $(28.3 \%$ true, $37.2 \%$ rather true, $\mathrm{N}=17410)$ or parties and candidates (31.2\% true, $36.9 \%$ rather true, $\mathrm{N}=17364$ ) with other citizens. smartvote users stated that the VAA was the most important instrument for getting information about parties and candidates for the 2007 elections among a list including all sorts of media channels, political events, advertisement and other online channels [27]. Similar results were found in a study on the German VAA Wahl-OMat. Almost $50 \%$ of users were motivated to search for more information on political issues after using the tool, $45 \%$ claimed that the VAA made them particularly attentive for special issues on the federal level and $70 \%$ stated that the use of the VAA motivated them to discuss the results of the voting recommendation with friends and family [19]. These results indicate that VAAs are not merely toys used by techsavvies but rather make citizens more attentive for political issues, motivate them to search for more information and makes them discuss politics with other citizens.

Since the motivation aspect can positively affect participation and consequently turnout, this aspect deserves closer attention. Our survey data of the smartvote users indicate that smartvote most likely had a positive impact on participation. $15.6 \%$ $(\mathrm{N}=17641)$ claimed that smartvote had motivated them to take part in the elections. Another $25 \%$ reveal that they have at least been partially motivated. The motivation effect of smartvote was significantly stronger among younger voters (see Table 3 ). 
Table 3. Impact of using smartvote on the decision to vote or not (in percentage) in the 2007 Swiss federal elections

\begin{tabular}{|c|c|c|c|c|c|c|}
\hline & $\begin{array}{l}\text { Definitely } \\
\text { motivated } \\
\text { me to vote }\end{array}$ & $\begin{array}{l}\text { Rather } \\
\text { motivated } \\
\text { me to vote }\end{array}$ & $\begin{array}{l}\text { No } \\
\text { influence }\end{array}$ & $\begin{array}{l}\text { Rather } \\
\text { prevented } \\
\text { me from } \\
\text { voting }\end{array}$ & $\begin{array}{l}\text { Definitely } \\
\text { prevented } \\
\text { me from } \\
\text { voting }\end{array}$ & $\mathbf{N}$ \\
\hline Total & 15.6 & 23.6 & 60.1 & 0.6 & 0.2 & $17^{\prime} 641$ \\
\hline \multicolumn{7}{|l|}{ Gender } \\
\hline Men & 12.7 & 23.7 & 62.6 & 0.5 & 0.2 & $12^{\prime} 214$ \\
\hline Women & 22.1 & 23.4 & 53.7 & 0.6 & 0.1 & 5'391 \\
\hline \multicolumn{7}{|c|}{ Age Groups } \\
\hline $18-24$ & 20.8 & 25.6 & 52.9 & 0.6 & 0.1 & 3'874 \\
\hline $25-34$ & 17.5 & 24.0 & 57.7 & 0.6 & 0.2 & $5^{\prime} 086$ \\
\hline $35-44$ & 13.7 & 23.2 & 62.5 & 0.5 & 0.2 & 3'633 \\
\hline $45-54$ & 11.9 & 22.7 & 64.7 & 0.6 & 0.1 & $2^{\prime} 505$ \\
\hline $55-64$ & 10.1 & 21.8 & 67.4 & 0.5 & 0.2 & 1'677 \\
\hline $65+$ & 9.5 & 20.3 & 69.5 & 0.5 & 0.1 & 739 \\
\hline
\end{tabular}

Source: own calculations

It is interesting to note that those who have been motivated the most by smartvote to vote in the elections are the young. We cannot rule out that other factors caused our respondents to cast their vote, however, since we did ask them directly if smartvote was the reason for their participation, we can deduce causality.

That high interest in politics results in participation is supported by the fact that in our sample more than $80 \%$ of those entitled to vote in 2007 also took part in the 2003 federal elections. Thus, it is not surprising that a majority of the respondents stated that they have not been influenced in their decision to vote or not since they participate regularly. If we take a closer look at those who did not vote in 2003, however, we do find a much stronger motivating effect (see Figure 2). Among those smartvote users who were eligible to vote in 2003 but abstained from voting, $41.4 \%$ claimed that the use of smartvote motivated them to take part in the 2007 elections. In comparison, $10.7 \%$ of users who already took part in 2003 stated that the use of smartvote motivated them to cast their vote in 2007 . Hence, the $41.4 \%$ of former nonvoters constitute a voting group that could have been mainly motivated through using smartvote to participate in the elections. Based on these numbers and given our absolute numbers of smartvote users plus those that filled in the questionnaire and the Swiss voter turnout for 2007, we can estimate that approximately 0,6-1,1\% of the voter turnout in the 2007 Swiss federal elections could have been due to smartvote. ${ }^{8}$ These numbers are estimates, but they might be even higher since we did not include

${ }^{8}$ These calculations are based on the assumption that those who filled out the smartvote questionnaire among users are representative for all smartvote users. Extrapolations lead to $14^{\prime} 368-25^{\prime} 127$ additional voters out of 2'373'071 total voters in the 2007 federal elections in Switzerland thanks to the use of smartvote. 


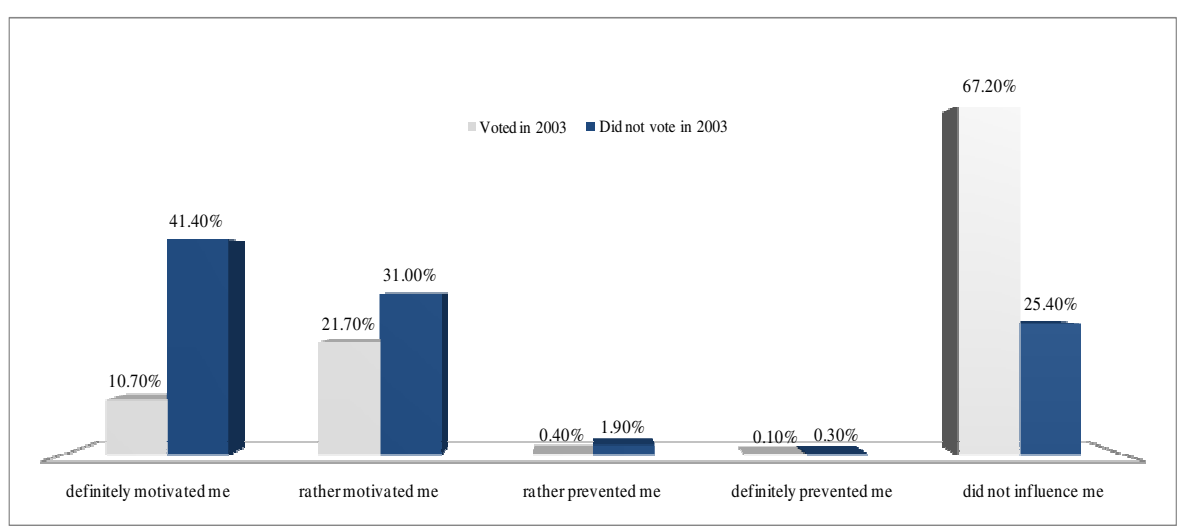

$\mathrm{N}$ voted in 2003: 12907; $\mathrm{N}$ did not vote in 2003 (but could have): 1402

Fig. 2. Did smartvote motivate you to take part in the 2007 Swiss federal elections? Comparing those who voted in 2003 to those who did not vote in 2003 (only those eligible to vote in 2003) Source: own calculations

the potential of new voters (young voting cohort) ${ }^{9}$ and those who did vote at both elections but only due to the motivating effect of smartvote.

If we take a closer look at those who were not yet eligible to vote in 2003 , the young voters, the motivating influence of smartvote is even stronger: $20.6 \%$ $(\mathrm{N}=2138)$ claimed that smartvote definitely motivated them to participate in the 2007 elections and $27 \%$ claimed that it rather motivated them to take part.

Overall, it can be summarized that smartvote does have a motivating effect; however, the effect is rather modest since most smartvote users are already motivated to participate in elections anyway. These findings are in line with results from other countries: A study on the German Wahl-O-Mat found that $7.8 \%$ of its users were motivated to cast a vote which they, before using the VAA, would not have done [19] and data from Finland's parliamentary election indicate that VAAs can mobilize voters with a low socio-economic status and increase the likelihood of voting by $21 \%$ for men and $23 \%$ for women [18].

Young voters with low education are particularly prone to abstain from voting. That smartvote is able to motivate this particular group of voters is promising for effects on electoral participation and turnout. Generally, at this stage it is difficult to evaluate the exact boost of smartvote on voting turnout - due to lack of representativity and possible self-selection in the survey and issues with casual mechanisms in the sample. Nevertheless, all indications point into the direction that VAAs - at least in the case of Switzerland - do have a positive impact on turnout, especially among those who do not participate regularly but are basically interested in politics. If the popularity of smartvote keeps on growing, the likelihood of its effect on voter turnout might increase. Even among those who are less interested in politics.

\footnotetext{
${ }^{9}$ The precondition for this calculation was that the respondent was already able to vote in 2003 . Thus, young voters that did not meet the voting age criteria by 2003 were not included.
} 


\section{Conclusion and Outlook}

The results of the analyses of the use of smartvote in the course of the 2007 Swiss federal elections show that VAAs do have an impact on elections. smartvote motivated citizens to participate in the elections, to search for more information about parties and candidates and to discuss politics with other citizens. The young disproportionally use smartvote and claim to have been motivated by the VAA to engage in politics and take part in the elections. Since young voters tend to abstain from voting, the mobilizing capacity of smartvote among this cohort is particularly promising. Our survey on the 2007 elections indicates that there was a group of former non-voters who were motivated by the tool to participate in the elections. Whether this group of former non-voters was made up of uninterested citizens, incompetent citizens or socially isolated citizens cannot be determined at this point, but leaves interesting opportunities for further research on the matter. If smartvote increases turnout of specific parts of society, it might be especially interesting to ask whether this favors specific candidates and parties.

Although we are optimistic about VAAs development, for now it has to be kept in mind that e-democracy tools such as smartvote are still young and are subject to further development. Yet, the data on its use is gathering up and, given its popularity, will soon offer the chance for longitudinal studies and more general conclusions. Favorably, similar data from other countries will soon allow comparative studies. For now, the descriptive analyses have produced first indications of an effect on electoral participation and voter turnout in Switzerland. Nevertheless, at this stage, cautiousness with regard to existing data has to be used. Further research is needed to investigate the casual mechanisms in our results. The potential of VAAs for affecting elections is, however, irrevocable.

That VAAs' potential might also bear negative aspects should not be neglected. Critics argue that VAAs might not necessarily be favourable for the democratic process since they offer the possibility of manipulating voting recommendations (by its developers or by parties) and thus distort the electoral process. Framing and fraud of such instruments might pose a threat to democracy, which makes scientific scrutiny indispensible. Especially since VAAs such as smartvote are developed by private actors - mostly on non-profit basis, however. The VAA under examination in this study is produced by scientists, proofed by experts, pre-tested in terms of its statement selections and transparent in its design. Hence, access to the calculation methods of smartvote, its financing sources and to the candidate answers on the smartvote questionnaire greatly reduce the aforementioned concerns. The ascribed negative potential of VAAs is further weakened through its monitoring capacities on political actors. Due to smartvote's transparency on candidate positioning, the voting behaviour of politicians once elected to office can be scrutinized, therewith strengthening accountability and consequently democracy.

For Switzerland, a main breakthrough for VAAs will come if e-voting will be standardized for voting processes. In systems like Switzerland, where voters not only send in party lists but take their time to customize their own list with cumulative and cross-voting, electronic devices that simplify these tasks will be very useful. Once you are able to copy-paste your choice of candidates - this can be up to 34 names in 
cantons such as Zurich - into the official ballot paper or send the ballot directly via remote internet-voting tools, the majority of citizens will eventually start to vote in the way they book their holidays nowadays.

But before this will become reality, today VAAs already render the possibility of bringing politics closer to the electorate. Through offering easy access to information they not only guide voters in their decision-making but might also spur changes in voting behavior. In the future, e-democracy tools such as VAAs will be easily accessible through a mobile phone or an ipad, offering a real chance of bringing voting decisions of citizens closer to their political preferences. With that, an increasing use of these tools will not only affect electoral participation, but also electoral campaigns and political parties. In other words, if voting decisions are increasingly based on issue stances, it will be interesting to analyze how political candidates will position themselves in the political space. VAAs not only make politics more accessible to citizens, they might also affect electoral processes and thus offer a new set of opportunities for electoral studies.

\section{References}

1. Lijphart, A.: Democracy's Unresolved Dilemma. The American Political Science Review 91(1), 1-14 (1997)

2. Kriesi, H.: Direct Democratic Choice. The Swiss Experience. Lexington Books, Oxford (2005)

3. Oser, F., Biedermann, H.: Jugend ohne Politik. Ergebnisse der IEA Studie zu Politischem Wissen, Demokratieverständnis und Gesellschaftlichem Engagement von Jugendlichen in der Schweiz im Vergleich mit 27 anderen Ländern. Zürich (2003)

4. Dalton, R.J.: Citizen Politics. Public Opinion and Political Parties in Advanced Industrial Democracies. CQ Press, Washington (2006)

5. Lutz, G.: Low Turnout in Direct Democracy. Electoral Studies 26, 624-632 (2007)

6. Norris, P.: Will New Technology Boost Turnout? Evaluating Experiments in UK Local Elections. In: Kersting, N., Baldersheim, H. (eds.) Electronic Voting and Democracy, New York, pp. 193-225 (2004)

7. Norris, P.: E-Voting as the Magic Ballot for European Parliamentary Elections? Evaluating E-Voting in the Light of Experiments in UK Local Elections. In: Trechsel, A.H., Mendez, F. (eds.) The European Union and E-Voting. Addressing the European Parliament's Internet Voting Challenge, London, pp. 60-90 (2004)

8. Trechsel, A.H.: Inclusiveness of Old and New Forms of Citizens' Electoral Participation. Representation 43(2), 111-121 (2007)

9. Norris, P.: Preaching to the Converted? Pluralism, Participation and Party Websites. Party Politics 9(1), 21-45 (2003)

10. Jeitziner, B.: Wahlen im Internetzeitalter. Informationsvermittler als politische Berater von Wählern und Politikern. In: Schaltegger, C.A., Schaltegger, S.C. (eds.) Perspektiven der Wirtschaftspolitik. Festschrift zum 65. Geburtstag von Prof. Dr. René L. Frey, pp. 47-64. vdf Hochschulverlag, Zürich (2004)

11. Leuchinger, S., Rosinger, M., Stutz, A.: The Impact of Postal Voting on Participation: Evidence for Switzerland. Swiss Political Science Review 13(2), 167-202 (2007)

12. Fivaz, J., Schwarz, D.: Nailing the Pudding to the Wall - E-Democracy as Catalyst for Transparency and Accountability. Paper Presented at the International Conference on Direct Democracy in Latin America, March 14-15, Buenos Aires, Argentina (2007) 
13. Walgrave, S., van Aelst, P., Nuytemans, M.: Do the Vote Test: The Electoral Effects of a Popular Vote Advice Application at the 2004 Belgian Elections. Acta Politica 43(1), 50-70 (2008)

14. Bühlmann, M., Freitag, M., Vatter, A.: Die Schweigende Mehrheit. Eine Typologie der Schweizer Nichtwählerschaft. In: Sciarini, P., Hardmeier, S., Vatter, A. (eds.) Schweizer Wahlen 1999, Bern, pp. 27-58 (2003)

15. Fivaz, J.: Impact of "smart-voting" on Political Participation. Working Paper Presented at the Civic Education and Political Participation Workshop at the Université de Montréal, June 17-19 2008, Montreal, Canada (2008)

16. Lutz, G.: Eidgenössische Wahlen 2007. Wahlteilnahme und Wahlentscheid. Lausanne (2008)

17. Ruusuvirta, O., Rosema, M.: Do Online Vote Selectors Influence Electoral Participation and the Direction of the Vote? Paper Presented at the ECPR General Conference, September 13-12, Potsdam, Germany (2009)

18. Mykkänen, J., Moring, T.: Dealigned Politics Comes of Age? The Effects of Online Candidate Selectors on Finnish Voters. Paper Presented at the Conference of Politics on the Internet: New Forms of Media for Political Action, November 25 , Tampere (2006)

19. Marschall, S.: Idee und Wirkung des Wahl-O-Mat. Aus Politik und Zeitgeschichte (APuZ) 51-52, 41-46 (2005)

20. Ladner, A., Felder, G., Fivaz, J.: Are Voting Advice Applications (VAAs) more than Toys? First Findings on Impact and Accountability of VAAs. IDHEAP Working Paper 2/2008, Lausanne (2008)

21. Carlson, T., Strandberg, K.: The 2004 European Parliament Election on the Web: Finnish Actor Strategies and Voter Responses. Information Polity 10(3-4), 189-204 (2005)

22. Downs, A.: An Economic Theory of Democracy. Harper and Row, New York (1957)

23. Palfrey, T.R., Poole, K.T.: The Relationship between Information, Ideology and Voting Behavior. American Journal of Political Science 31(3), 511-530 (1987)

24. Delli Carpini, M.X., Keeter, S.: What Americans Know about Politics and Why It Matters. Yale University Press, New Haven (1996)

25. Kirchgässner, G., Feld, L.P., Savioz, M.R.: Die Direkte Demokratie. Modern, Erfolgreich, Entwicklungs- und Exportfähig. Verlag Franz Vahlen, München (1999)

26. Dalton, R.J.: Democratic Challenges - Democratic Choices. The Erosion of Political Support in Advanced Industrial Democracies, Oxford (2007)

27. Ladner, A., Felder, G., Schädel, L.: From E-voting to smart-voting. E-Tools in and for Elections and Direct Democracy in Switzerland. Paper Presented at the Conference 'Direct Democracy in and Around Europe: Integration, Innovation, Illusion, and Ideology' at the Center for Democracy Aarau, October 3 (2008) 